\title{
Mães psicólogas ou psicólogas mães: vicissitudes na educação dos filhos
}

\author{
Thaís Thomé Seni da Silva e Oliveira \\ Regina Helena Lima Caldana \\ Universidade de São Paulo - Ribeirão Preto
}

\begin{abstract}
Resumo
No processo de alterações de valores ocorrido durante o século XX, a Psicologia e a Psicanálise emergiram como saberes norteadores para a conduta dos pais, e sua difusão tem sido considerada fonte de dificuldades para estes. Este trabalho busca contribuir para a compreensão do papel de tais saberes na vivência de mães, através de entrevistas realizadas com mães psicólogas atuantes clinicamente com orientação psicanalítica. Utilizou-se a história de vida temática, que prevê inicialmente o relato da história de vida, complementada por um conjunto de tópicos previamente definidos pelo pesquisador. As entrevistas foram gravadas, transcritas e analisadas qualitativamente. Resultados apontam que a importância do contato e trabalho com Psicologia e Psicanálise para a maternidade envolve a dimensão do conhecimento teórico e também do trabalho emocional na própria análise, que permite uma assimilação diferenciada do conhecimento técnico. Um outro dado não previsto e enfatizado foi a vivência da maternidade modificando a atuação profissional.
\end{abstract}

Palavras chave: práticas educativas; crenças parentais; psicanálise

\begin{abstract}
Psychologist mothers or mother psychologists: vicissitudes in childrearing practices. In the process of change of values occurred in the $20^{\text {th }}$ century, Psychology and Psychoanalysis emerged as scientific guides for parents ' behavior, and their diffusion has been considered source of difficulties for them. This work intends to contribute to the understanding of the role of such knowledge systems, through interviews with psychologist mothers who work as psychotherapists in psychoanalytical orientation. Thematic history of life was used at first, foreseeing the narrative of history of life, complemented by a set of topics previously defined by the researcher. The interviews were recorded, transcribed and qualitatively analyzed. Results point to the importance of contact and work with Psychology and Psychoanalysis for maternity involving the dimension of theoretical knowledge and also the emotional work in self analysis, allowing a differentiated assimilation of technical knowledge. A not foreseen and emphasized datum was the experience of maternity modifying professional performance.
\end{abstract}

Keywords: childrearing practices; parental beliefs; psychoanalysis

$\mathrm{E}$ ducar um filho hoje traz consigo uma série de dúvidas e angústias aos pais, que se sentem inseguros quanto ao seu papel e ao modo de educar: O que é certo? Que postura tomar? Como e quando exercer autoridade? Ser amigo dos filhos? O que permitir e o que proibir? Quais as conseqüências de suas ações no desenvolvimento dos filhos?

Porém, o olhar para a história das práticas educativas nos mostra que tal enfoque e preocupação a respeito da criação e desenvolvimento dos filhos é algo de nosso tempo. Ariès (1981) afirma que atualmente somos "obcecados" pelos problemas físicos, morais e sexuais da infância, convidando-nos a um olhar para a História que deixa patente o quanto essa mentalidade é recente.

E qual é o objetivo da educação de filhos? A ação de quem educa guia-se por objetivos imediatos e mediatos, que são determinados por valores sócio-histórico e cultu- ralmente estabelecidos (Caldana, 1994). Em outras palavras, a conduta do educador é guiada pelo ideário, pelos valores e costumes do contexto no qual está inserido. Tais valores de alguma forma determinarão as imagens da criança ideal e do adulto ideal de determinado contexto sócio-histórico-cultural, que certamente influirão nos objetivos da educação.

Com efeito, Newson e Newson (1974) trazem a noção de que $o$ aspecto mais interessante da preocupação contemporânea com as práticas educativas é a consciência e atenção às possíveis consequiências psicológicas dos métodos que se usam na criação de uma criança. Isto é um fenômeno novo, já que as gerações anteriores de pais estiveram especialmente preocupadas com temas relacionados à sobrevivência física e ao desenvolvimento moral, mais do que com conceitos de saúde mental e bem-estar emocional. 
No contexto do Brasil, este processo traz algumas particularidades: as descrições referentes ao século XVIII e parte do XIX, voltadas para a realidade familiar das elites, apontam o modelo familiar patriarcal e a presença da escravidão como aspectos definidores da forma e cuidado de educação dos filhos, na medida em que eles determinavam que o universo familiar fosse centrado no adulto, que houvesse uma rígida demarcação de papéis, valorização da autoridade, e que não sobrasse espaço para a afetividade. Soma-se a isso a presença de forte religiosidade, a preocupação com a formação moral, a ausência ou não expressão de afeto, o alto índice de mortalidade infantil e a exacerbação da autoridade paterna e da submissão dos filhos (Caldana,1998).

Ao longo do século XIX com a formação do Estado Nacional, o desenvolvimento urbano, a substituição das grandes propriedades rurais de monocultura pela diversificação de agentes econômicos e abolição da escravatura, esse modelo familiar começa a ser modificado, aproximando-se do modelo familiar burguês europeu (Costa, 1983). Um fator importante foi a força do discurso higienista, que coloca entre nós a figura do médico como fonte de diretrizes para as práticas educativas familiares.

O processo de modernização societária segue seu curso e se intensifica principalmente a partir da segunda metade do século XX (Winckler, 1983), com reflexos diretos na família e na subjetividade dos sujeitos, num processo que está longe de ser considerado simples.

Segundo Figueira (1987), até por volta da década de 1950 teria prevalecido em nossa sociedade o ideal de família tradicional, descendente direto da família patriarcal; nela a identidade dos membros é posicional, ou seja, é determinada pelas suas características intrínsecas (homem e mulher, pai e filho), que os apresentam como naturalmente diferentes, o que determina uma rígida delimitação de papéis. As regras de conduta são definidas externamente, por valores dicotômicos, onde certo e errado são muito bem delimitados. Sucedendo a esse ideal, ainda que de forma absolutamente não-linear, teríamos o da família igualitária, em que a identidade dos sujeitos passa a ser idiossincrática: homens e mulheres, pais e filhos são iguais enquanto indivíduos; as diferenças são atribuídas à individualidade de cada sujeito, que seria livre para optar, e as escolhas não são consideradas necessariamente certas ou erradas de antemão. É importante frisar que para a emergência deste modelo igualitário, foi de grande importância a difusão da Psicologia e da Psicanálise entre nós (Russo, 1987).

Pesquisas voltadas diretamente para o estudo das alterações das práticas e valores que sustentam a educação da criança na família neste século (Biasoli-Alves, 1995; Caldana 1991, 1998; Dias-da-Silva, 1986; Gomes, 1987; Zagury, 1992, 2000) apontam para um sentido das mudanças afinado à transição de um ideário tradicional para um moderno. Sua expressão mais enfática seria a presença de um enfoque antiautoritário aliado à preocupação com a felicidade da criança, traduzida como bem-estar emocional, e à importância atribuída à expressão de afeto e à proximidade através do brincar. Dois outros aspectos salientam-se nestes estudos: a constância de conflitos paternos oriundos tanto da inexistência de um padrão claro de conduta comumente aceito, como da dificuldade em colocar limites e exercer a autoridade, mesmo quando esse exercício não poderia ser considerado "autoritário", e a forte influência de idéias ligadas à Psicologia e Psicanálise, que faz com que a preocupação com a felicidade da criança seja equivalente a buscar sua saúde emocional.

Silva Neto (1988, p. 25), em seu estudo sobre as percepções, cognições e sentimentos de mães ligados ao criar filhos, traz considerações sobre o acesso destas, como leigas, ao universo de informações advindas da Psicologia e da Psicanálise, agrupando tais informações em quatro crenças principais, que acabariam por nortear suas condutas com o filho: (1) o desenvolvimento sadio da personalidade depende das experiências da infância; (2) o calor emocional e todos aqueles afetos incluídos no complexo denominado amor materno servem de base para o crescimento físico, social e psíquico da criança; (3) a mãe, na função de mediadora entre a criança e o espaço social, exerce papel fundamental no processo de adaptação da criança ao mundo dos adultos; e (4) a individualidade da criança deve ser compreendida, respeitada e atendida.

Mas se, na situação atual, encontramos, por um lado, a dificuldade na tarefa de educar filhos e, por outro, a difusão da Psicologia e da Psicanálise, saberes que emergem como norteadores para os pais, isso não quer dizer que exista entre esses dois aspectos uma relação de causa e efeito simples; pelo contrário, ambos com certeza podem ser compreendidos como frutos de um processo social e cultural bastante complexo. Aponta Kitzinger (1978) que, a partir de uma visão transcultural do fenômeno, quanto mais se escreve sobre maternidade, paternidade e práticas educativas, mais os pais se perguntam se estão educando o filho de maneira correta. No entanto, têm sido raras as ocasiões em que o conhecimento ligado à Psicologia e à Psicanálise tem sido responsabilizado diretamente por pelo menos uma parcela das dificuldades dos pais (Zagury, 1992). Estamos, com certeza, lidando com uma dimensão imensamente ampla da questão, e, para os propósitos deste trabalho, parece-nos importante ao menos considerar que entre o conhecimento produzido em Psicologia, sua divulgação pela mídia e a forma de sua apreensão pelos pais com certeza existem grandes diferenças.

\section{Objetivos}

Este trabalho, que se constitui num recorte de uma pesquisa mais ampla ${ }^{1}$, pretende trazer uma contribuição para o estudo de práticas educativas contemporâneas, no que diz respeito às dificuldades vivenciadas por pais na educação de seus filhos, e ao papel das idéias oriundas da Psicologia e da Psicanálise nesta situação.

Tendo em vista as considerações sobre o cuidado e educação de filhos em nosso contexto atual, podemos introduzir a seguinte questão: o que acontece com a mãe que tem acesso ao conhecimento legítimo do universo de informações relativos à Psicologia, de modo geral, e à Psicanálise, mais especificamente?

A indagação deste estudo volta-se então para o que ocorreria com a própria mãe que é uma profissional $p s i$, de certo modo a parcela da população que é porta voz por excelência do 
ideário ligado à Psicologia e Psicanálise. Ou, de outra forma, de que maneira a assimilação técnica deste conhecimento se reflete na tarefa de educação de filhos? Neste sentido, propõe-se investigar como o papel de mãe e o processo de socialização e educação dos filhos é vivenciado por mulheres que têm formação teórica e prática em Psicologia, com direcionamento para a área clínica com referencial psicanalítico.

Sem desprezar a importância do papel do pai e das vicissitudes da paternidade, o presente trabalho restringe-se ao modo como a mãe vivencia o papel materno em nosso contexto. Neste sentido, vários pesquisadores apontam que, apesar das mudanças sociais referentes à família e ao papel da mulher com a emancipação feminina através de sua inserção no domínio do público, a mulher ainda exerce influência predominante no domínio do privado, ou seja, do ambiente familiar, incluindo a criação de filhos (Baptista, 1995; Chodorow, 1990; Hermanson-Rosa, 2000).

\section{Método}

\section{Entrevistas}

A partir da consideração de que crenças e atitudes dos pais são determinadas por um conjunto amplo de fatores, entre os quais seu contexto sócio-cultural, seu nível de conhecimento, sua história de vida, as experiências vividas, suas necessidades motivacionais, conflitos intrapsíquicos e estado de desenvolvimento pessoal, Miller (1988), Palacios (1990) e Lightfoot e Valsiner (1992), consideram importante a utilização de entrevistas abertas. Elas permitem identificar teorias explícitas e implícitas adotadas pelos pais, como definem ou representam as situações vividas, como concebem o desenvolvimento da criança, do que consideram que ela é, de como e em que extensão pode ser influenciada e de como suas ações repercutem no desenvolvimento e na vida do filho.

Dessa maneira, considerando o objetivo deste trabalho, optou-se pela realização das entrevistas segundo o modelo denominado história de vida temática. Segundo Meihy (1994), tal modalidade de entrevista engendra tanto a opinião ou posicionamento do sujeito sobre determinado evento, quanto seu ponto de vista em relação aos fatos e significados de sua própria história de vida. Nessa mesma direção, Queiroz (1987) comenta que ao reconstituir sua história de vida através do relato ao pesquisador, o narrador não só traz aspectos particulares de sua experiência, mas também se refere à sua existência através do tempo, quando são delineadas suas relações com os membros de seu grupo, de sua profissão, de sua família e de seu contexto social como um todo. Assim, caberia ao pesquisador captar aquilo que ultrapassa o individual e que se insere nas coletividades a que o narrador pertence.

Esse modelo de entrevista pressupõe a realização de entrevistas em dois momentos. Inicialmente, solicita-se ao entrevistado o relato da sua história de vida com mínima interferência do entrevistador. Esgotada esta etapa, o pesquisador busca a complementação das informações já obtidas, de acordo com uma série de tópicos previamente definidos (Apêndice A), caracterizando-se a entrevista, neste momento, como semi-estruturada.
Não se pode deixar de mencionar, além disso, o trabalho ético de cuidadoso tratamento das informações que poderiam eventualmente levar à identificação dos sujeitos como: nomes de pessoas, instituições em que trabalha ou trabalhou, da universidade em que se graduou, e cursos freqüentados. Vale ressaltar que este trabalho ético de preservação do sigilo sobre a identidade dos sujeitos foi redobrado em função da natureza da pesquisa e do público de interesse (sendo este predominantemente de psicólogos, a identificação dos entrevistados poderia ocorrer em função de pequenos detalhes).

As entrevistas foram realizadas no primeiro semestre do ano de 2000, no local de trabalho das participantes (consultório particular), em uma ou duas sessões de aproximadamente uma hora cada. As entrevistas foram realizadas, gravadas e transcritas na íntegra por uma das pesquisadoras.

\section{Participantes}

Os dados coletados são referentes às entrevistas realizadas com mulheres, profissionais graduadas em Psicologia, com atuação profissional na área clínica de orientação psicanalítica. Considerou-se condição para a participação na pesquisa que estas profissionais tivessem tido seu primeiro filho depois de pelo menos dois anos de experiência profissional, estando este filho, no momento de realização da entrevista, com idade entre quatro e dez anos. A primeira destas condições teve o objetivo de garantir certo nível de apropriação da abordagem teórica a partir da experiência profissional, e a segunda, de constituir um corpo de dados com homogeneidade em relação ao tipo de experiência na educação dos filhos em função da sua idade.

As participantes foram selecionadas a partir da indicação de conhecidos, recurso esse adotado face à natureza da pesquisa, que por envolver profissionais da área como pesquisadores e entrevistados, e por abordar conteúdos de caráter muito íntimo e pessoal, exigia, para a concordância na participação, uma relação de confiança a priori. As pessoas indicadas foram contatadas e consultadas quanto à possibilidade de sua participação na pesquisa, tendo manifestado sua concordância como consta do Termo de consentimento livre e esclarecido utilizado.

Foram realizadas cinco entrevistas, número definido em função da natureza exploratória da pesquisa, da modalidade da entrevista, bem como pela adoção de metodologia qualitativa, tendo como pano de fundo o critério de ponto de saturação. Todas as entrevistadas eram provenientes da classe média da sociedade e graduadas em Psicologia em duas universidades públicas de cidades interioranas do estado de São Paulo, tendo concluído o curso há mais de 10 anos. Encontravam-se na faixa etária de 30 a 40 anos e a maioria tinha dois filhos. Todas estavam casadas com profissionais liberais, estando a maioria deles vinculados à área de saúde. Além de estarem atuando em consultório particular, as entrevistadas tinham experiência profissional como psicólogas em instituições, sendo que duas delas ainda mantinham esse vínculo profissional (Tabela 1). Estes cuidados de seleção foram tomados no sentido de garantir alguma uniformidade no tempo de experiência destas mulheres como profissionais e como mães. 
Tabela 1

Caracterização das entrevistadas (*)

\begin{tabular}{|c|c|c|c|c|c|}
\hline Nome & Filhos & Sexo & Idade (anos) & Trabalho atual & Profissão do marido \\
\hline Iara & 2 & $\begin{array}{l}\text { Masculino } \\
\text { Feminino }\end{array}$ & $\begin{array}{l}5 \\
1\end{array}$ & Consultório & $\begin{array}{l}\text { Prof. liberal da área da } \\
\text { saúde }\end{array}$ \\
\hline Márcia & 1 & Masculino & 5 & Consultório & $\begin{array}{l}\text { Prof. liberal da área da } \\
\text { saúde }\end{array}$ \\
\hline Cecília & 2 & $\begin{array}{l}\text { Feminino } \\
\text { Masculino }\end{array}$ & $\begin{array}{l}7 \\
4\end{array}$ & Consultório & Profissional liberal \\
\hline Isa & 2 & $\begin{array}{l}\text { Feminino } \\
\text { Feminino }\end{array}$ & $\begin{array}{l}7 \\
3\end{array}$ & $\begin{array}{l}\text { Instituição e } \\
\text { consultório }\end{array}$ & $\begin{array}{l}\text { Prof. liberal da área da } \\
\text { saúde }\end{array}$ \\
\hline Laura & 2 & $\begin{array}{l}\text { Feminino } \\
\text { Masculino }\end{array}$ & $\begin{array}{l}7 \\
4\end{array}$ & $\begin{array}{l}\text { Instituição e } \\
\text { consultório }\end{array}$ & $\begin{array}{l}\text { Prof. liberal da área da } \\
\text { saúde }\end{array}$ \\
\hline
\end{tabular}

(*) Todas entrevistadas realizaram trabalho anterior em "instituição e consultório"

\section{Análise dos dados}

As entrevistas foram analisadas de acordo com o modelo proposto por Biasoli-Alves, e Dias-da-Silva (1992), que prevê a sistematização das informações obtidas através de leitura sucessivas do material, que se acompanham de anotações de tudo o que se apreende dos dados e do que eles significam, levando em conta tanto suas regularidades quanto diferenças. Este trabalho é acompanhado de um movimento constante entre dados, abordagem conceitual e a literatura a respeito do tema, até que se atinja um quadro de análise significativo e compreensivo. Segundo este modelo, o momento da redação é essencial, consistindo a etapa final da análise.

Este procedimento prevê uma seqüência em que, numa primeira etapa, lida-se com as entrevistas uma a uma, procedendo-se à sua análise temática, e posteriormente trabalhase de forma transversal, reunindo-se os recortes referentes a cada tema de todas entrevistas (Bardin, 1975), tendo como referência seu significado em relação ao objetivo principal da pesquisa.

Neste trabalho apresentamos a análise referente ao conjunto de temas diretamente relacionados à maternidade e à formação profissional, tal como identificado no conjunto das entrevistas.

\section{Resultados e discussão}

\section{A Psicologia e a Psicanálise no olhar para a própria história}

Apresentamos os resultados da análise deste trabalho começando pela releitura feita pelas entrevistadas de suas experiências passadas, quando chamadas a falar de sua própria história de vida.

O olhar para a própria infância, adolescência e de si enquanto filhas, como também da família de origem, aparece filtrado e reinterpretado a partir do conhecimento teórico sobre o universo psicológico e o desenvolvimento emocional. As angústias sentidas no passado passam a ter uma compreensão no presente em função deste contato com teorias. É o passado sendo interpretado no presente a partir da (in)formação profissional. No mesmo sentido, falam sobre a própria família de origem, e em especial sobre a própria mãe. Dinâmicas familiares passam a ser vistas como problemáticas e emergem modelos ideais implícitos: a mãe continente às angústias do filho, que realiza verdadeiras trocas afetivas num vínculo profundo, e que assim fornecerá ao filho condições para seu desenvolvimento através do partilhar de intimidade e da percepção deste. Tal ideal vem acompanhado daquilo que dele se afasta e que, portanto, é considerado negativo: a ansiedade e a depressão da mãe. Fica evidente que ao entrar em contato com estas experiências passadas com a mãe, referem-se a falhas e faltas em relação ao modelo que hoje possuem. Exemplos:

É, eu acho que durante o período em que eu estava em casa, parece que eu não sentia os problemas como eu sinto hoje, eu acho que até porque o tempo passa, minha mãe é deprimida, eu não tinha essa noção antes, né? Hoje eu tenho. E aí eu hoje vejo a minha família de uma maneira bem diferente que eu via anteriormente, né? Parece que era tudo muito mais idealizado e agora tá tudo muito mais caótico. (Cecília) ${ }^{2}$

(...) lembrando um pouco do relacionamento da minha mãe comigo, né? eu também penso que havia dificuldade de conversar, de expressar o afeto. Então essas coisas foram me chamando a atenção, do relacionamento mais íntimo dos pais com os filhos, de poder tá mais junto, de acompanhar mais o crescimento, o desenvolvimento, de tá fazendo mais trocas afetivas com o filho, isso é uma coisa que eu acho que eu sinto que é importante, que até faltou um pouco, né? (Isa)

\section{A Psicologia e a Psicanálise na maternidade: atenção à vida emocional}

Os relatos são, a todo momento, permeados pela atenção e valorização da parte emocional tanto do filho, quanto de si, quanto daquela que envolve o par mãe-criança. O modelo ideal trazido pelo conhecimento e a importância dada ao desenvolvimento e expressão da afetividade, além de estar presente na ressignificação de suas experiências passadas como filhas, guia também a mãe-psicóloga no contato com seu filho. As entrevistadas descrevem a experiência de ser mãe como uma situação singular e especial, que, envolvendo permanentemente a vivência de emoções intensas, acaba por modificar o mundo afetivo da mulher, sua identidade, e propi- 
cia condições peculiares para seu desenvolvimento como pessoa. O relato a seguir ilustra essas situações.

Acho que é diferente você realmente viver ali, vivenciar uma relação, um vínculo desse, amoroso, de mãe e filho, eu acho que é difícil você imaginar isso, né? Então esse tipo de coisa eu acho que é muito forte, e aí cê tem que viver pra saber. (Isa)

No mesmo sentido, as entrevistadas trazem a preocupação em oferecer aos filhos espaço e condições para que ocorra a expressão e elaboração de emoções, apontando para a priorização do emocional perante o cognitivo e a valorização do lúdico e da liberdade.

O enfoque sobre as emoções e sobre o modo como a criança está lidando com estas é sempre evidente. Interpretam comportamentos do filho a partir de seu referencial teórico, lançando mão de conteúdos e conceitos psicológico-psicanalíticos tais como: a intensidade e o teor das angústias do bebê e da criança, a comunicação inconsciente entre mãe e filho influenciando o estado emocional de ambos, a rivalidade entre irmãos, a tolerância à frustração e o modo de expressão das emoções. Evidencia-se um ideal de criança calcado na imagem da extroversão, no sentido da expressão das emoções no ambiente e na relação com o grupo de pares, como pode ser visto no exemplo abaixo.

Até hoje ela tem essa característica, que eu acho que é dela mesmo desde bebê, ela mostrou assim, a impressão que me dá é que ela tem uma tolerância menor à frustração, e que eu tenho que ser mais dura com ela, pôr mais limite. Mas é mais expressiva, né? tem isso. (Isa)

\section{A Psicologia e a Psicanálise: da mãe idealizada à mãe humanizada.}

A concepção de que os pais deverão suprir as necessidades da criança e oferecer condições para seu desenvolvimento cognitivo e afetivo, retoma o já referido modelo ideal de mãe no qual se entrevê a presença da formação, e parece trazer mais preocupação à mãe-psicóloga que procura se encaixar nesse ideal. A responsabilidade no papel de mãe vem então intensificada por estas concepções.

Por outro lado, a vivência intensa da responsabilidade tem as culpas e cobranças da mãe para consigo mesma relativizadas por concepções em outra direção: o entendimento de que as atitudes maternas dependem de uma "condição interna" fora do controle da própria pessoa, e não de conhecimentos ou intenção deliberada e consciente, desobrigando de uma cobrança auto-imposta de corresponder a modelos ideais. Dessa maneira, o mesmo referencial que aprisiona a mãe-psicóloga também a liberta: "a gente é a mãe que a gente pode ser" (Iara).

Temos, porém, uma relação bastante dinâmica e complexa entre o aumento da responsabilidade e a relativização dela. Por exemplo, os momentos de descontrole emocional, considerados negativos e prejudiciais, são compreensíveis a partir da humanização da mãe, mas evitados e seus efeitos são entendidos como passíveis de reparação. Exemplo:
Apesar de depois ter as angústias por não ter pensado, por ter agido dessa maneira, quer dizer, eu acho que o que muda pra mim, o fato de eu fazer análise, e ter estudado um pouco mais essas questões, é que eu procuro pensar muito nisso depois, e tentar reparar quando dá. (Isa)

\section{Mãe em análise}

Ao tratar da atenção e importância atribuídas ao seu próprio emocional, a análise pessoal, instrumento essencial da formação profissional dentro desta abordagem, é bastante valorizada, parecendo constituir um espaço que propicia à mãepsicóloga o auto-conhecimento e a elaboração do que apreende das informações teóricas e de suas experiências cotidianas nos diversos papéis que desempenha. Por exemplo:

O que mais me ajudou no papel de mãe, se alguma coisa... toda teoria e tal ajuda, não é nem a teoria, é a vivência mesmo. É o fato de tá em análise, isso sim eu acho que influenciou muito em muitos momentos assim. (Iara)

É importante ressaltar que a formação do psicoterapeuta de orientação psicanalítica, assim como de outras abordagens, inclui seu trabalho de análise ou psicoterapia pessoal, aliando ao conhecimento teórico um aprendizado sobre si mesmo, envolvendo um permanente contato com sua própria vida afetiva e um processo de desenvolvimento contínuo, tanto no papel profissional como pessoal. Exemplo:

É interessante porque quanto mais você adquire a maturidade, o auto-conhecimento em análise, a experiência profissional, quanto mais você tem isso, tem mais condição de compreender algumas coisas até como mãe, você tem mais esclarecimento a respeito da tua função materna. (Isa)

\section{Em avaliação o ser mãe sendo psicóloga}

Quando indagadas diretamente acerca das interferências da formação profissional no exercício da maternidade, as entrevistadas consideram que o contato com todo "conhecimento psicológico" acrescenta outra dimensão às experiências vividas, passando a integrar indissociavelmente a visão de mundo da mãe-psicóloga, e torna impossível o exercício da maternidade à sua revelia.

No entanto, essa relação não é apresentada em uma única perspectiva. Um aspecto bastante positivo levantado pelas entrevistadas é o de poder fazer uso do que aprendeu para fornecer ao filho oportunidades diferenciadas para aquilo que valorizam, como a expressão de emoções e a possibilidade de uma relação autêntica e intensa, com mais continência às necessidades do filho. Assim, relatam que, em certos momentos, aplicam seu aprendizado teórico-vivencial na relação com o filho, considerando isso como um ganho e um diferencial em relação à mãe leiga. O acesso ao saber sobre o desenvolvimento infantil traz a essas mães gratificações e prazeres especiais por conhecerem mais do assunto. Exemplos:

É tão gostoso, tão bonito acompanhar e ver seu filho aprendendo a pensar, tendo as aquisições dele, né? (Márcia)

Se eu sei que é bom, eu vou procurar oferecer isso pras minhas filhas. (Isa) 
Por outro lado, podemos dizer que as entrevistadas fazem alusão, de modo indireto, a duas vertentes da Psicologia e da Psicanálise: o referencial normatizador, que pressupõe modelos ideais de comportamento e desenvolvimento, em que o indivíduo deve encaixar-se; e o referencial relativizador, que considera cada indivíduo como único, que age e sente de acordo com suas possibilidades. O primeiro deles traz uma dificuldade a mais, ao criar uma expectativa que pode não ser satisfeita; e o segundo, um conforto, denotando mais uma vez ambivalência na relação com o conhecimento.

No entanto, quando convidadas mais diretamente a fazer um balanço, as mães acabam por enfatizar aspectos negativos deste contato, apontando para a sobrecarga de uma psicologização de suas vivências como mãe. Exemplo:

Eu acho que o fato da profissão, tem uma exigência assim, uma expectativa, né? de que ele dê certo, que se encaixe nesse modelo de saúde mental. Isso eu não acho legal não. Porque cê acaba pondo uma expectativa em cima da criança, ... tem uma piadinha que fala assim: que casa de engenheiro e filho de psicólogo todo mundo quer ver, né? Como se ele fosse o cartão de visita da mãe. (Iara)

\section{Ser psicóloga sendo mãe: da maternidade à postura profissional}

O último tema a ser abordado, refere-se à configuração de um aspecto trazido espontaneamente pelas entrevistadas e que inverte o eixo explorado até o momento: a maternidade modificando a esfera profissional e o trabalho da mãe como psicóloga.

Se atuar como psicólogo clínico na abordagem psicanalítica requer um trabalho emocional intenso do profissional, a experiência intensiva de ser mãe e cuidar de uma criança certamente será refletida na profissão. Assim, fala-se da modificação da atuação profissional através da vivência da maternidade, referindo-se a mudanças na forma de se relacionar com seus pacientes, em especial crianças, e maior empatia com as mães que atendem, como também na releitura e compreensão num outro nível do conhecimento teórico. Exemplo:

Eu lembro que quando eu comecei a atender criança; antes de ser mãe era de um jeito, hoje em dia eu tenho uma sensibilidade muito diferente daquela época, muito diferente. (Isa)

\section{Conclusões}

Podemos iniciar nossas reflexões sobre este trabalho, trazendo a percepção de que, a todo momento, os relatos das mães-psicólogas são permeados por sua formação profissional. Assim, o olhar para seu passado, para o filho e para si mesmas sofre a influência do conhecimento que possuem.

As entrevistadas foram enfáticas em dizer que o conhecimento que possuem em Psicologia e Psicanálise não é apenas referente às teorias, mas também ao vivencial, às suas experiências de vida aliadas ao seu trabalho emocional contínuo, que se propõem a fazer através da análise pessoal, cujo valor dentro do campo e da abordagem em que atuam é imprescindível.
Assim, a análise pessoal é apontada como importante para uma apreensão mais adequada do conhecimento teórico e para uma avaliação autocrítica de suas atitudes. Ao se referirem a este processo permanente de contato e elaboração das próprias vivências emocionais, trazem a noção de que o profissional dessa área, especificamente da psicologia clínica de orientação psicanalítica, constrói sua formação aliando ao conhecimento teórico um trabalho e aprendizado constante em relação a si próprio, que não se constitui em trabalho intelectual apenas, mas que envolve o contato com suas próprias emoções e um processo contínuo de crescimento e flexibilização para lidar melhor com seu mundo interno e externo.

Esta parece ser uma das principais características deste tipo de profissão, em que a pessoa do profissional é seu próprio instrumento de trabalho, e por isso precisa cuidar de si mesmo, algo reafirmado do período inicial (Freud, 1907/ 1969) ao momento atual na Psicanálise (Castro, 1993).

No geral, podemos dizer que a informação teórica será apropriada pela mãe de formas diversas, de acordo com o momento e sua condição emocional. Trazem então, o contato com esse saber psi em diferentes dimensões, apontando aspectos como o uso intelectual e deliberado do conhecimento, visando fornecer recursos diferenciados para o desenvolvimento do filho. Por outro lado, em situações emocionais extremas, o conhecimento teórico deixa de nortear a conduta, aparecendo reações mais impulsivas, freqüentemente consideradas inadequadas. Aqui surge um outro ponto que parece peculiar à mãe-psicóloga: a possibilidade de reflexão posterior a estas reações e a tentativa de reparação na relação com o filho.

Perante essa formação, emerge o olhar diferenciado da mãe-psicóloga, que focaliza comportamentos pelo que traduzem de desenvolvimento cognitivo e emocional do filho, em termos da adequação ao previsto nas diferentes fases. Além disso, o conhecimento teórico e técnico permeia o olhar autocrítico que estas mães lançam sobre si mesmas, ao apoiarem-se em modelos ideais de maternidade, de acordo com o considerado necessário para o bom desenvolvimento da criança.

O maior destaque é dado à dimensão afetiva que, no que diz respeito ao filho, refere-se à importância das fases primitivas do desenvolvimento, a valorização da liberdade e da expressão de emoções e na atenção às angústias da criança; como contrapartida, salienta-se a responsabilidade em relação a ser continente às necessidades do filho.

Em suas referências diretas sobre o tema, na visão que trazem sobre a relação psicologia e maternidade, apesar de apresentarem aspectos positivos e negativos, as mães-psicólogas enfatizam os últimos, como o aumento da angústia e do senso de responsabilidade para com o filho, e também uma certa tendência à psicologização de suas relações interpessoais, incluindo a maternidade.

De maneira indireta, no entanto, dizem que nessa relação com a profissão, com os filhos e consigo mesmas, vão transformando-se e desenvolvendo-se. Desta forma, um aspecto não previsto e muito trazido pelas entrevistadas foi o enriquecimento e modificação da atuação profissional, bem como 
a possibilidade de releitura mais profunda e madura do conhecimento teórico, proveniente da vivência da maternidade.

A partir destas considerações tecidas a respeito das mãespsicólogas, voltamo-nos agora para um contexto mais amplo.

Encontramos na literatura sobre maternidade, maternagem e práticas de educação de filhos referentes às mães leigas, elementos que trazem aproximações e diferenciações com relação ao panorama traçado para as mães psicólogas. Deste modo, um primeiro ponto em comum entre estes dois grupos refere-se a aspectos sócio-culturais e à "mentalidade" atual, em que o foco é sem dúvida na dimensão da subjetividade e na vida emocional das pessoas, sejam elas adultos ou crianças (Caldana, 1991). Assim, a preocupação com o universo emocional do sujeito, considerado em sua individualidade, faz parte de aspectos culturais contemporâneos, não sendo de forma alguma, restrita às mães-psicólogas. Na mesma direção, um outro ponto ressaltado, refere-se à noção de responsabilidade e culpa dos pais que, da mesma maneira, parecem fazer parte de nosso ideário contemporâneo, pela preocupação e necessidade estabelecida de oferecer condições ótimas para o desenvolvimento da criança (Silva Neto, 1988).

Diante de todas estas considerações, fica implícito que, seja para mães e pais em geral, seja para mães-psicólogas, atualmente o educar tem como pano de fundo principal o propiciar saúde mental ao indivíduo, em detrimento da transmissão de valores morais (Caldana, 1998).

Evidentemente há diferenças, e estas dizem respeito principalmente à possibilidade que as mães psicólogas têm de reflexão e trabalho emocional consigo mesmas, pela própria natureza de sua formação e atuação profissional, o que dá um tom e um colorido diferente no contato com as idéias provenientes do universo psi. Para estas mães oferece-se, ao lado de elementos que aumentam potencialmente a noção de sua responsabilidade, um recurso para fazer frente à vivência possivelmente acentuada de culpa decorrente, o que não ocorre com as mães leigas. Aqui, reforça-se a idéia de que, numa dimensão cultural, não é o teor das idéias ligadas à Psicologia e à Psicanálise que acrescenta dificuldades aos pais, mas, sim, a própria forma de difusão e apropriação desse conhecimento.

Dessa maneira, comparando-se a situação de mães-psicólogas e mães leigas, poderíamos concluir que este se trata de um importante diferencial a ser considerado: a análise pessoal a que se submetem as mães-psicólogas acaba se tornando um espaço de reflexão e apropriação afetiva das teorias científicas e do conhecimento intelectual.

E como fica a mãe leiga? Nesse sentido, concordamos com autores que consideram importante a criação de espaços, não necessariamente em contexto clínico, onde mães e pais em geral possam trocar experiências, informações e sentimentos em relação a criar filhos, ao seu papel, ao que pensam, sentem e fazem. Knobel (1996) considera que seria importante, além disso, trabalhar com a realidade política, social e econômica, contextualizando as práticas educativas e promovendo a integração do papel de mãe e pai ao de cidadão com visão crítica da realidade e dos fenômenos. Em ambos os grupos a conclusão é a mesma: teoria e informa- ção são insuficientes e precisam ser significados nas vivências de quem educa.

\section{Referências}

Ariès, P (1981). História social da família e da criança. Rio de Janeiro: Zahar. Bardin, L. (1975). Análise de conteúdo. Lisboa: Edições 70.

Baptista, S. M. S. (1995). Maternidade e profissão: oportunidades de desenvolvimento. São Paulo: Casa do Psicólogo.

Biasoli-Alves, Z. M. M. (1995). Família e socialização: processos, modelos e momentos. Tese de Livre Docência não-publicada, Universidade de São Paulo, Ribeirão Preto.

Biasoli-Alves, Z. M. M., \& Dias da Silva, M. G. F. (1992). Análise qualitativa de dados de entrevista. Paidéia - Cadernos de Educação da FFCL-RP USP, 2, 61-69.

Caldana, R. H. L. (1991). Família: mulher e filhos. Três momentos numa revista católica brasileira (1935 a 1988). Dissertação de Mestrado não-publicada, Universidade Federal de São Carlos, São Carlos.

Caldana, R. H. L. (1994). Interdisciplinaridade e a orientação do educador. Paidéia - Cadernos de Educação da FFCL RP-USP, 7, 11-18.

Caldana, R. H. L. (1998). Ser criança no início do século: alguns retratos e suas lições. Tese de Doutorado não-publicada, Universidade Federal de São Carlos, São Carlos.

Castro, M. L. S. (junho de 1993). Reflexões sobre análise didática. Comunicação apresentada em Mesa Redonda da Sociedade Brasileira de Psicanálise de São Paulo, São Paulo.

Chodorow, N. (1990). Psicanálise da maternidade: uma crítica a Freud a partir da mulher. Rio de Janeiro: Rosa dos Tempos.

Costa, J. F. (1983). Ordem médica e norma familiar. Rio de Janeiro: Graal.

Dias-da-Silva, M. H. G. (1986). A educação dos filhos pequenos nos últimos cinqüenta anos: a busca do melhor? Dissertação de Mestrado não-publicada, Universidade de São Paulo, São Paulo.

Figueira, S. A. (1987). O "moderno" e o "arcaico" na nova família brasileira: notas sobre a dimensão invisível da mudança social. In I. Ribeiro (Org.), Uma nova família? O moderno e o arcaico na família de classe média brasileira (pp.11-30). Rio de Janeiro: Imago.

Freud, S. (1969). Obras completas (Vol. XII, pp. 125-133). Rio de Janeiro: Imago. (Texto original publicado em 1907)

Gomes, J. V. (1987). Socialização: um estudo em famílias de migrantes em bairros periféricos de São Paulo. Tese de Doutorado não-publicada, Universidade de São Paulo, São Paulo.

Hermanson-Rosa, L. H. (2000). Mulher e maternidade. Dissertação de Mestrado não publicada, Universidade de São Paulo, Ribeirão Preto.

Kitzinger, S. (1978). Mães: um estudo antropológico. Lisboa: Presença.

Knobel, M. (1996). Orientação familiar. Campinas: Papirus.

Lightfoot, C., \& Valsiner, J. (1992). Parental belief systems under the influence: social guidance of construction of personal cultures. In I. E. Sigel, A. V. McGillicuddy de Lisi, \& J. J. Goodnow (Org.), Parental belief systems: the psychological consequences for children (pp. 84-117). Hillsdale: Lawrence Erlbaum.

Meihy, J. C. S. B. (1994). Definindo história oral e memória. Cadernos CERU, 2(5), 52-60.

Miller, S. A. (1988). Parents' beliefs about children's cognitive development. Child Development, 59, 259-285.

Newson, T., \& Newson, E. (1974). Cultural aspects of childrearing in the English-speaking world. In M. P. M. Richard (Org.), The integration of $a$ child into a social world (pp. 53-82). Londres: Cambridge.

Palacios, J. (1990). Parents' ideas about development and education of their children.answer to some questions. International Journal of Behavioral Development, 13(2), 137-155.

Queiroz, M. I. P. (1987). Relatos orais: do "indizível" ao "dizível". Ciência e Cultura, 39(3), 272-286. 
Russo, J. A. (1987). A difusão da psicanálise nos anos 70: indicações para uma análise. In I. Ribeiro, I. (Org.), Família e valores (pp. 189-204). São Paulo: Loyola.

Silva Neto, N. A. (1988). Fragmentos da metamorfose: cuidado materno e cuidado psicoterapêtico. São Paulo: Edusp.
Winkler, C. R. (1983). Pornografia e sexualidade no Brasil: da repressão a dessublimação. Porto Alegre: Mercado Aberto.

Zagury, T. (1992). Sem padecer no paraíso: em defesa dos pais ou sobre a tirania dos filhos. Rio de Janeiro: Record.

Zagury, T. (2000). Limites sem trauma. Rio de Janeiro: Record.

Nota

1 Este trabalho traz um recorte de dados oriundos do projeto de pesquisa Pais psicólogos ou psicólogos pais: vicissitudes na educação dos filhos, desenvolvido como pesquisa de iniciação científica.

2 Os nomes empregados são fictícios.

Thaís Thomé Seni da Silva e Oliveira é mestranda no Departamento de Psicologia e Educação da Faculdade de Filosofia Ciências e Letras de Ribeirão Preto, Universidade de São Paulo. E-mail: ththome@ itelefonica.com.br Regina Helena Lima Caldana, doutora em Educação pela Universidade Federal de São Carlos, é professora no Departamento de Psicologia e Educação, Faculdade de Filosofia Ciências e Letras de Ribeirão Preto, Universidade de São Paulo. Endereço para correspondência: Universidade de São Paulo, Faculdade de Filosofia Ciências e Letras de Ribeirão Preto, Departamento de Psicologia e Educação; Avenida Bandeirantes, 3900; Ribeirão Preto, SP; CEP 14040-901; Tel.: (16) 602-3804. Fax: (16) 633-5015. E-mail: rhlcalda@ffclrp.usp.br 


\section{Apêndice A}

\section{Tópicos norteadores e complementares}

1. A própria educação

Como foi a criação recebida, em termos gerais

Percepção sobre os pais, em especial da mãe

2. Opção profissional

O que levou a optar pela formação em Psicologia

Onde estudou

O que estudou, no geral e em pontos específicos (teorias a respeito da criança, do desenvolvimento cognitivo e emocional, do papel da educação no desenvolvimento, na socialização primária, e na formação da personalidade)

Concepções sobre a educação da criança, o papel da mãe e do pai que a formação na graduação trouxe

Concepções sobre a educação da criança, o papel da mãe e do pai que a experiência profissional trouxe

3. Vida profissional

Formação (cursos, especializações, pós-graduação)

Prática

4. Maternidade

Casamento e vida de casada

Momento em que nasceram os filhos

Contar como foi o bebê até a idade em que a criança está

Cuidado concreto - descrição

Interação com a criança - descrição

Conciliação com o trabalho

Idéias e expectativas anteriores, e as mudanças com a experiência

5. Paternidade

Cuidado concreto - descrição

Interação com a criança - descrição

Divisão das tarefas com a mãe

Idéias e expectativas anteriores, e as mudanças com a experiência

6. Criança

Imagens, expectativas e mudanças com a experiência

7. Educação de filhos

imagens, expectativas e mudanças com a experiência

Como vê o papel que a formação, com as informações ligadas à Psicologia, teve em suas experiências com o filho

Maiores preocupações atuais com os filhos, e relação das mesmas com a formação

8) Acha que as pessoas têm representações ou expectativas do seu desempenho como mãe em função da formação / atuação profissional? Qual? 